\title{
Surface transformation of ram spermatozoa in uterine, oviduct and cauda epididymal fluids in vitro
}

\author{
J. K. Voglmayr and R. F. Sawyer, Jr \\ Division of Reproductive Biology, Florida Institute of Technology, $150 \mathrm{~W}$. University Boulevard, \\ Melbourne, Florida 32901, U.S.A.
}

\begin{abstract}
Summary. Genital tract fluids were collected continuously from conscious ewes through catheters inserted surgically into the uterus and oviducts. Cauda epididymal spermatozoa and fluid were obtained through catheters inserted into the transected vas deferens. The washed spermatozoa were labelled using the surface-specific chloroglycoluril- $\mathrm{Na}^{125}$ I procedure. High-resolution electrophoretic analysis of sperm plasma membrane preparations revealed a partial loss of a major surface component (i.e. $M_{\mathbf{r}}$ 97000 ) during incubation in uterine and oviduct fluids. This specific loss resulted in a shift in radioactivity distribution toward an $M_{\mathrm{r}} 24000$ component which had been previously identified as a sialoglycoprotein. No significant changes in the distribution of radiolabelled surface components were detectable when the spermatozoa were incubated in synthetic medium. Incubation of unlabelled spermatozoa in ${ }^{125}$ I-labelled uterine fluid showed that adsorption of exogenous fluid components was highly selective; an $M_{\mathrm{r}} 16000$ polypeptide was greatly enriched on the sperm surface although it was only a minor component in the incubation fluid. Adsorption of labelled oviduct fluid components was also selective and involved predominantly high molecular weight components (i.e. $M_{\mathrm{r}} 140000,95000,78000,53000$ ). When spermatozoa were incubated in labelled cauda epididymal fluid after exposure to unlabelled uterine and oviduct fluids, several fluid components were incorporated by the plasma membrane, indicating that surface renovation of 'capacitated' spermatozoa may be a more general process rather than a specific event. These results suggest that capacitation of ram spermatozoa involves loss of specific surface proteins as well as selective adsorption of exogenous fluid components and point to a polypeptide in uterine fluid as an active constituent.
\end{abstract}

\section{Introduction}

The delay in fertilization after insemination of small rodents prompted Austin (1951) and Chang (1951) to conclude that mammalian spermatozoa must be exposed for a time to female reproductive tract secretions before they can fertilize oocytes. During this time spermatozoa undergo several biochemical and biophysical changes collectively referred to as capacitation (Farooqui, 1983; Meizel, 1984, 1985). These include changes in motility (Cornett \& Meizel, 1978), calcium flux (Singh, Babcock \& Lardy, 1978) and lectin binding (Talbot \& Franklin, 1978), rearrangement of plasma membrane autoantigens and particles (Friend, 1980), changes in plasma membrane phospholipid composition (Davis, Byrne \& Bedigia, 1980), loss of surface-associated inhibitory components (Fraser, 1984) and other surface modifications (O'Rand, 1982). Some immunochemical studies have described the removal of a specific surface component and perhaps have overemphasized the partial loss of a single component as being the major factor in a mechanism underlying capacitation. The fact that an antibody which recognizes a single antigenic determinant on the sperm surface blocks fertilization does not necessarily make it the major factor 
of capacitation. This process evidently involves numerous components of the sperm cell surface and the fluid in which the spermatozoa are suspended.

Fertilization has been successfully performed in vitro for man and small laboratory rodents. However, when this technique was applied to large domestic animals few fertilized ooctyes were obtained, even when the spermatozoa had been prepared for fertilization in the oviduct in vivo (Wright \& Bondioli, 1981). Attempts should be made to study the interaction of female reproductive tract fluid components with spermatozoa in the hope of identifying factors that enhance fertilization in vitro. In the present study we have collected uterine and oviduct fluids separately from oestrous ewes to determine the major sperm surface components lost into these fluids during incubation in vitro and we have characterized components from female and male reproductive tract fluids that are absorbed by spermatozoa.

\section{Materials and Methods}

Collection of uterine and oviduct fluids. Six Dorset ewes, aged 3-4 years were used during the breeding season (September-February). They were made to stand in metabolism cages in a light- $(12 \mathrm{~h} /$ day $)$ and temperature- $\left(16^{\circ} \mathrm{C}\right)$ controlled environment. The general approach for cannulating the oviducts was similar to that described by Restall (1966a) with the following modifications: the Silastic (Dow Corning Co., Midland, MI) catheter ( $1.0 \mathrm{~mm}$ i.d., $2 \cdot 1 \mathrm{~mm}$ o.d.) was bifurcated. About $1 \mathrm{~cm}$ of each end of the Y-shaped catheter was inserted through the fimbria into the oviducts and secured by placing a 4-0 silk suture around the tubes above a cuff on the catheter, similar to a technique used previously to cannulate the rete testis of rams (Voglmayr, Scott, Setchell \& Waites, 1967). After ligation of the utero-tubal junctions by means of a 3-0 silk suture, $12 \mathrm{~cm}$ of a straight catheter of the same internal diameter and wall thickness as described above were inserted into a uterine horn through a puncture incision about $2 \mathrm{~cm}$ from the uterotubal junction and secured by means of a purse-string suture (4-0) above a cuff. This catheter had multiple perforations to facilitate entry of fluid into its lumen. The free ends of the catheters were exteriorized through puncture incisions on the rear flank of the animal. The fluids were collected separately into $2 \mathrm{ml}$-capacity polyethylene tubes on the flank whence they were transferred continuously by means of a peristaltic pump into $12 \mathrm{ml}$ graduated centrifuge tubes on ice. The tubes were exchanged every 12 or $24 \mathrm{~h}$. After the volume had been recorded, the fluids were centrifuged at $5000 \mathrm{~g}$ in the cold and residual cellular debris was removed by passing the fluid through a Millipore filter $(0 \cdot 45 \mu \mathrm{m}$ pore size $)$.

Collection and preparation of spermatozoa and fluids. Spermatozoa were collected from 3 Dorset rams through catheters inserted surgically into the transected vas deferens (Voglmayr et al., 1977). The spermatozoa were washed twice in calcium-free Ringer phosphate ( $\mathrm{pH} 7 \cdot 4$; Umbreit, Burris \& Stauffer, 1959) with added lactate $(10 \mathrm{~mm})$ as substrate. For recovery of cauda epididymal fluid (CEF), freshly collected epididymal semen was centrifuged at $10000 \mathrm{~g}$ for $20 \mathrm{~min}$ at $4^{\circ} \mathrm{C}$. Residual cellular debris was eliminated by passing the fluid through a Millipore filter (see above). All fluids were stored at $-20^{\circ} \mathrm{C}$ and diluted with equal volumes of Ringer phosphate- $10 \mathrm{~mm}$-lactate before use to increase their buffering capacity and to provide additional substrate for spermatozoa.

Radioiodination procedures. Washed cauda spermatozoa were labelled using the surface-specific method of Markwell \& Fox (1978) with the modifications described by Voglmayr, Fairbanks, Vespa \& Colella (1982). To each chloroglycoluril-coated $(50 \mu \mathrm{g}$, Pierce Chemical Co., Rockford, IL) Pyrex glass tube were added $0.5 \mathrm{ml}$ sperm suspension $\left(\sim 2 \times 10^{8}\right.$ cells $)$ and $0.5 \mathrm{mCi}$ carrier-free $\mathrm{Na}^{125} \mathrm{I}$ (sp. act. $\sim 15 \mathrm{mCi} / \mu \mathrm{g}$ : Amersham Co., Arlington Heights, IL). Fluids $(0.5 \mathrm{ml})$ were labelled with $2-3 \mathrm{mCi} \mathrm{Na}{ }^{125} \mathrm{I}$. After incubation at room temperature for $10 \mathrm{~min}$, the labelled spermatozoa were washed three times in large volumes $(10 \mathrm{ml})$ of Ringer phosphate. Labelled fluids were dialysed against large volumes $(3 \times 600 \mathrm{ml})$ of Ringer phosphate as described previously (Voglmayr, Fairbanks, Jackowitz \& Colella, 1980). 
Incubation of spermatozoa. To study losses of surface components into reproductive tract secretions of the ewe, washed ${ }^{125} \mathrm{I}$-labelled spermatozoa $\left(2-3 \times 10^{8}\right.$ cells $\left./ \mathrm{ml}\right)$ were incubated in non-labelled uterine fluid and/or oviduct fluid at $37^{\circ} \mathrm{C}$. To compensate for the dilution $(1: 1 \mathrm{v} / \mathrm{v})$ of the fluids with Ringer, the spermatozoa were incubated in uterine and oviduct fluid for $1 \mathrm{~h}$ and $3 \mathrm{~h}$, respectively, or more than twice the average time required for capacitation of ram spermatozoa in vivo (Mattner, 1963). After $1 \mathrm{~h}$ incubation in uterine fluid, a sample was removed to assess the motility on a warm microscopic stage and to determine the surface labelling pattern. To separate the highly motile spermatozoa from uterine fluid, a centrifugal force of up to $1500 \mathrm{~g}$ had to be applied. The spermatozoa were washed twice in large volumes of Ringer-phosphate and the fluid was centrifuged again at $5000 \mathrm{~g}$ to remove all spermatozoa. The remainder of the reaction mixture was centrifuged at $1500 \mathrm{~g}$ for $7 \mathrm{~min}$ and the cell-free uterine fluid was quickly aspirated and replaced with oviduct fluid. After a further $3 \mathrm{~h}$ of incubation in oviduct fluid, the spermatozoa were separated from the fluid and washed. All fluid samples used for electrophoretic analysis were passed through a $0.45 \mu \mathrm{m}$ filter to remove residual cellular debris.

For identification of adsorbed fluid components, unlabelled spermatozoa were incubated in radioiodinated uterine fluid at $37^{\circ} \mathrm{C}$ for $1 \mathrm{~h}$. To study adsorption of components from oviduct fluid, spermatozoa were first exposed to unlabelled uterine fluid for $1 \mathrm{~h}$ followed by incubation in labelled oviduct fluid for $3 \mathrm{~h}$. For studies of surface renovation of 'capacitated' spermatozoa in cauda epididymal fluid, cells which had been exposed to unlabelled uterine and oviduct fluid for $1 \mathrm{~h}$ and $3 \mathrm{~h}$, respectively, were incubated in radiolabelled cauda epididymal fluid for $2 \mathrm{~h}$. After incubation, the spermatozoa were separated from the fluid and washed as described above.

Sample preparation and electrophoretic analysis. Sperm and fluid samples were prepared for SDS-PAGE as described previously (Voglmayr et al., 1980, 1982) except that the spermatozoa were subjected to a brief ultrasonification $(2-3 \mathrm{~min})$ at $0^{\circ} \mathrm{C}$ immediately after addition of SDS and heating at $95^{\circ} \mathrm{C}$ for $2 \mathrm{~min}$. The suspensions were centrifuged at $2500 \mathrm{~g}$ for $5 \mathrm{~min}$ to remove DNA before final processing of the samples. Proteins were fractionated using a two-dimensional system in which the proteins were first separated on an SDS tube gel followed by resolution in the second dimension in a slab gel with a sigmoidal gradient (Liu, Fairbanks \& Palek, 1977). A human erythrocyte ghost preparation was co-chromatographed with the second dimension for molecular weight calibration (Voglmayr et al., 1980). The gels were stained with Coomassie blue (Fairbanks, Steck \& Wallach, 1971) and radioactive surface components were localized by autoradiography using a LightningPlus intensifying screen (Cronex, Du Pont de Nemours \& Co., Wilmington, DE).

Radioactivity distribution of surface components. Changes in radioactivity distribution of labelled surface components were assessed as follows. Bands identified on the dried gel by autoradiography were carefully cut out and collected into $1 \times 7 \mathrm{~cm}$ glass tubes for radioactivity measurements in a Beckman gamma 5500 counting system. The largest band on a set of autoradiographs was used as standard for the areas that were cut out for a given radioactive protein and they were of exactly the same size between treatments, irrespective of variations on the autoradiographs. After the sum of the major radioactive spots had been calculated, changes in the distribution of individual components between treatments could then be assessed. To eliminate errors due to variations in resolution of the gels and exposure of the autoradiographs, each experiment was replicated four times.

Motility measurements. After each treatment the motility of the spermatozoa was assessed using the characteristics described by Mattner \& Voglmayr (1962). A drop of sperm suspension was placed into a microscopic slide chamber $(0.4 \mathrm{~mm}$ deep) on a warm stage. The speed and frequency of the mass wave motion was assessed at low magnification while the proportion of actively progressing spermatozoa was determined in a thin film at high magnification. The motility was scored from 0 (immotile) to 5 (maximal motility). 


\section{Results}

\section{Secretion of fluids}

In 5 ewes the catheters remained patent through 1-4 oestrous cycles. In one ewe the catheters became blocked soon after surgery. From the intervals between the flow of uterine fluid and the peaks of oviduct fluid secretion it can be calculated that the average $( \pm$ s.e.) length of an oestrous cycle in Dorset ewes was $17.8 \pm 0.59$ days $(n=11)$. The daily amount of uterine fluid collected ranged from 0.0 to $12.1 \mathrm{ml}$ and that of oviduct fluid from 0.2 to $7.0 \mathrm{ml}$. Figure 1 shows typical patterns of secretion from the uterus and oviduct of a 3-year-old Dorset ewe. The length of the oestrous cycle varied by 3-4 days and each major peak of oviduct fluid secretion was followed by a smaller secondary peak after 4-6 days.

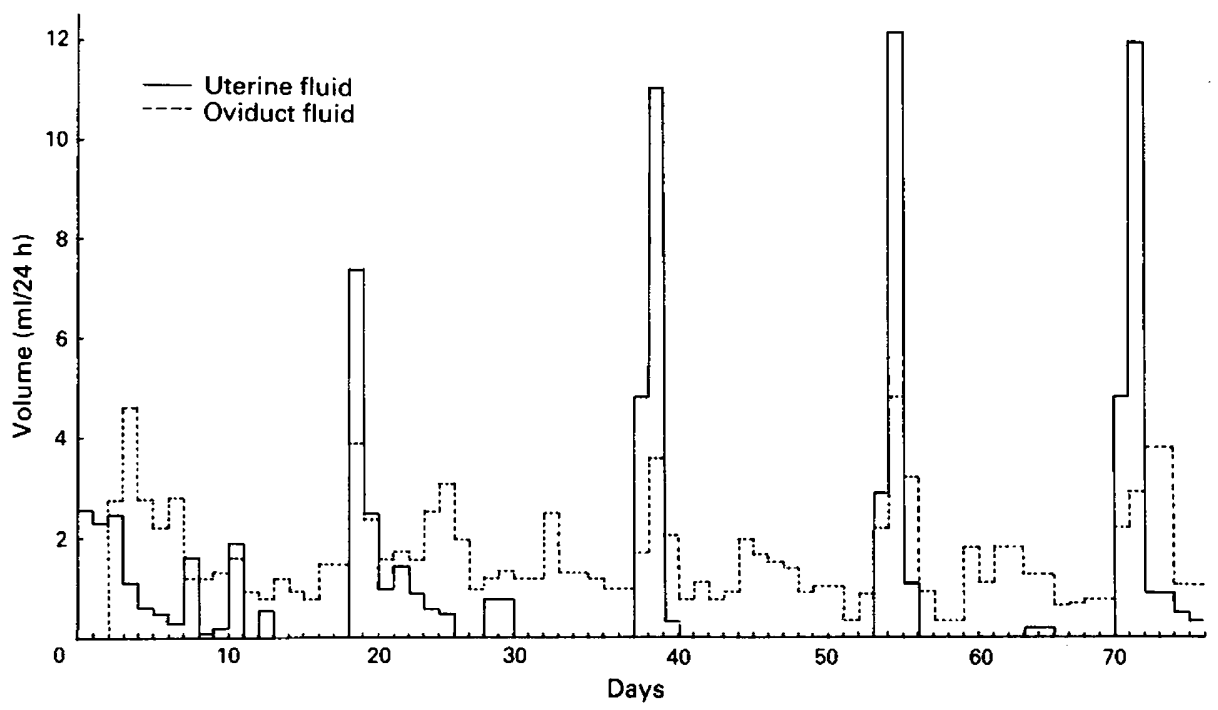

Fig. 1. Daily secretion of uterine (-) and oviduct (-- ) fluids of a conscious ewe. Intervals between peaks of fluid output correspond approximately to oestrous cycles.

\section{Polypeptide composition of fluids}

The protein staining patterns of the reproductive tract secretions of the ewe are shown in Fig. 2. The predominant components in uterine and oviduct fluid had a relative molecular mass of 66000 , presumed to be serum albumin. While several components are common to both fluids (e.g. $M_{\mathrm{r}}$ $230000,150000,30000)$, the low molecular weight species characteristic of uterine fluid $\left(M_{\mathrm{r}}\right.$ $<30000$ ) were not detectable in oviduct fluid or appeared only as minor components on the electrophoretogram. Although one-dimensional electrophoretic analysis of selected oviduct fluid samples collected throughout the oestrous cycle showed no significant differences in their protein staining pattern (not shown), it was assumed that there may be differences in their potency to alter the surface characteristics of the spermatozoa. Therefore, only samples obtained during the 3-4-day period of high flow rate (oestrus) were used for study.

\section{Effect of uterine and oviduct fluids on the distribution of labelled surface components}

Incubation of ${ }^{125} \mathrm{I}$-labelled cauda epididymal spermatozoa in unlabelled uterine fluid and oviduct fluid at $37^{\circ} \mathrm{C}$ for $1 \mathrm{~h}$ and $3 \mathrm{~h}$, respectively, resulted in a shift in radioactivity distribution of 

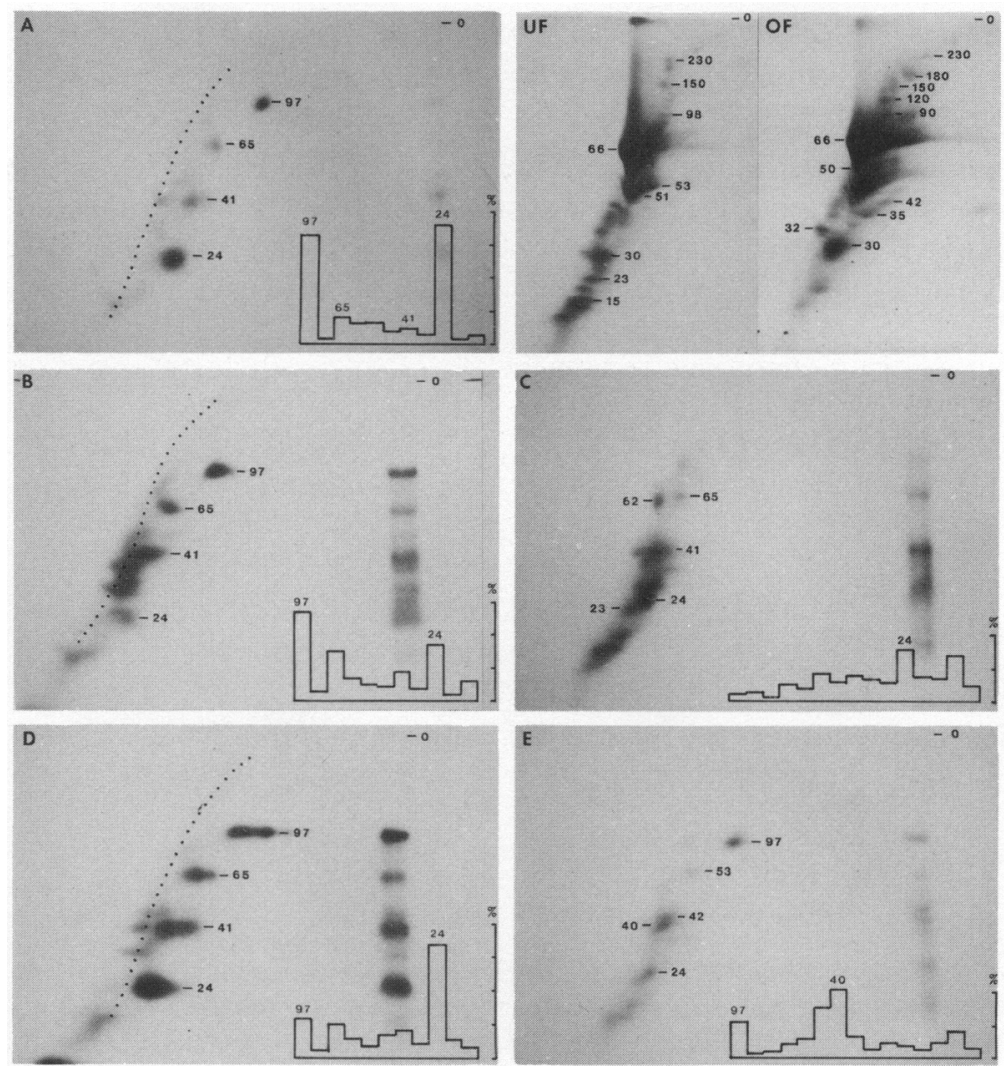

Fig. 2. Effects of uterine (UF) and oviduct (OF) fluids on the radioactivity distribution of major intrinsic surface components $\left(\times 10^{-3}\right)$ of ${ }^{125}$ I-labelled cauda spermatozoa: (A) surface labelling pattern and radioactivity distribution (insert) of freshly collected spermatozoa; (B) spermatozoa after incubation in UF for $1 \mathrm{~h}$; (D) spermatozoa after incubation in UF and $O F$ for $1 \mathrm{~h}$ and $3 \mathrm{~h}$, respectively; $(\mathrm{C}, \mathrm{E})$ radioactivity distribution of the major surface components lost into fluids. Scale of inserts in $10 \%$ increments. UF, OF, protein staining patterns of fluids used.

the surface labelling pattern. In freshly collected cauda spermatozoa the two predominant surface components (i.e. $M_{\mathrm{r}} 97000$ and 24000 ) were about equally distributed (Fig. 2A), but the former was selectively removed during incubation in oviduct fluid, after a $1 \mathrm{~h}$ exposure to uterine fluid, so that by $4 \mathrm{~h}$ the $M_{\mathrm{r}} 24000$ component emerged as the predominant feature (Fig. 2D). Radioactivity of the labelled surface proteins lost into the fluids more or less mirrored the shift in the distribution of the major surface components (Figs 2C, 2E). In contrast, when spermatozoa were incubated in Ringer phosphate for $1 \mathrm{~h}$ and $4 \mathrm{~h}$, there were no changes in the distribution of the major surface components (Figs $3 \mathrm{~A}, 3 \mathrm{C}$ ). This was also reflected in the radioactivity pattern of the suspending medium resulting from the dissociation of labelled surface components during incubation (Figs 3B, 3D).

\section{Adsorption of labelled uterine fluid components}

Adsorption of radioiodinated uterine fluid components by unlabelled spermatozoa was highly selective. During incubation in labelled uterine fluid for $1 \mathrm{~h}$ a low molecular weight polypeptide $\left(M_{\mathrm{r}}\right.$ 

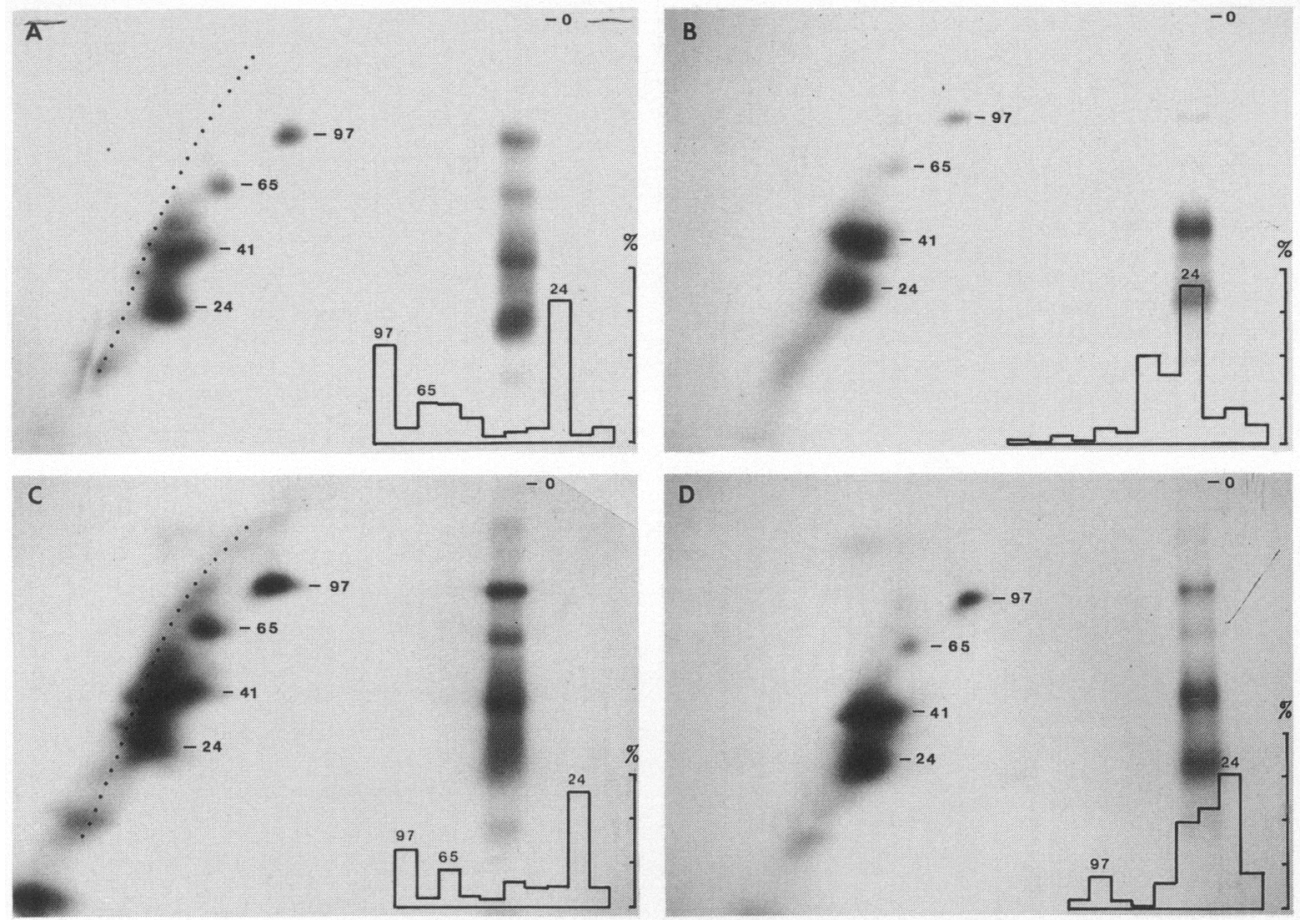

Fig. 3. Radioactivity distribution of major intrinsic surface components $\left(\times 10^{-3}\right)$ of labelled cauda spermatozoa after incubation in Ringer phosphate for $1 \mathrm{~h}$ (A) and $4 \mathrm{~h}$ (C). (B, D) radioactivity of major surface components lost into the incubation medium after $1 \mathrm{~h}$ and $4 \mathrm{~h}$ incubation. No major shifts occurred in the radioactivity distribution of surface components (initial, Fig. 2A).

16000 ) was consistently enriched on the sperm surface (Fig. 4C), even though it represented only a 'minor' component in the fluid (Figs 4B, 4D). Traces of a band identified as $M_{\mathrm{r}} 29000$ were also detectable on the sperm surface. The location of the two adsorbed components on or near the 'diagonal' (Fig. 4C, dotted line) suggests that they may be species with a relatively low carbohydrate content (Bretscher, 1971).

\section{Adsorption of labelled oviduct fluid components}

When washed unlabelled cauda spermatozoa were incubated in radioiodinated oviduct fluid for $3 \mathrm{~h}$, after exposure to unlabelled uterine fluid for $1 \mathrm{~h}$, an adsorption pattern was obtained that was also indicative of selectivity (Fig. 5C). Adsorbed oviduct fluid components were of relatively high molecular weight (i.e. $M_{\mathrm{r}} 140000,95000,78000,53000$ ), all of which appeared on the electrophoretogram of the fluid as relatively minor bands (Fig. 5D). In addition, a component of $M_{\mathrm{r}}$ 66000 , believed to be serum albumin, migrated above the 'diagonal' and was a major feature of the adsorption pattern.

\section{Adsorption of labelled cauda epididymal fluid components}

Incubation of spermatozoa in radioiodinated cauda fluid for $2 \mathrm{~h}$ after exposure to unlabelled uterine and oviduct fluids for $1 \mathrm{~h}$ and $3 \mathrm{~h}$, respectively, yielded the adsorption pattern shown in Fig. 

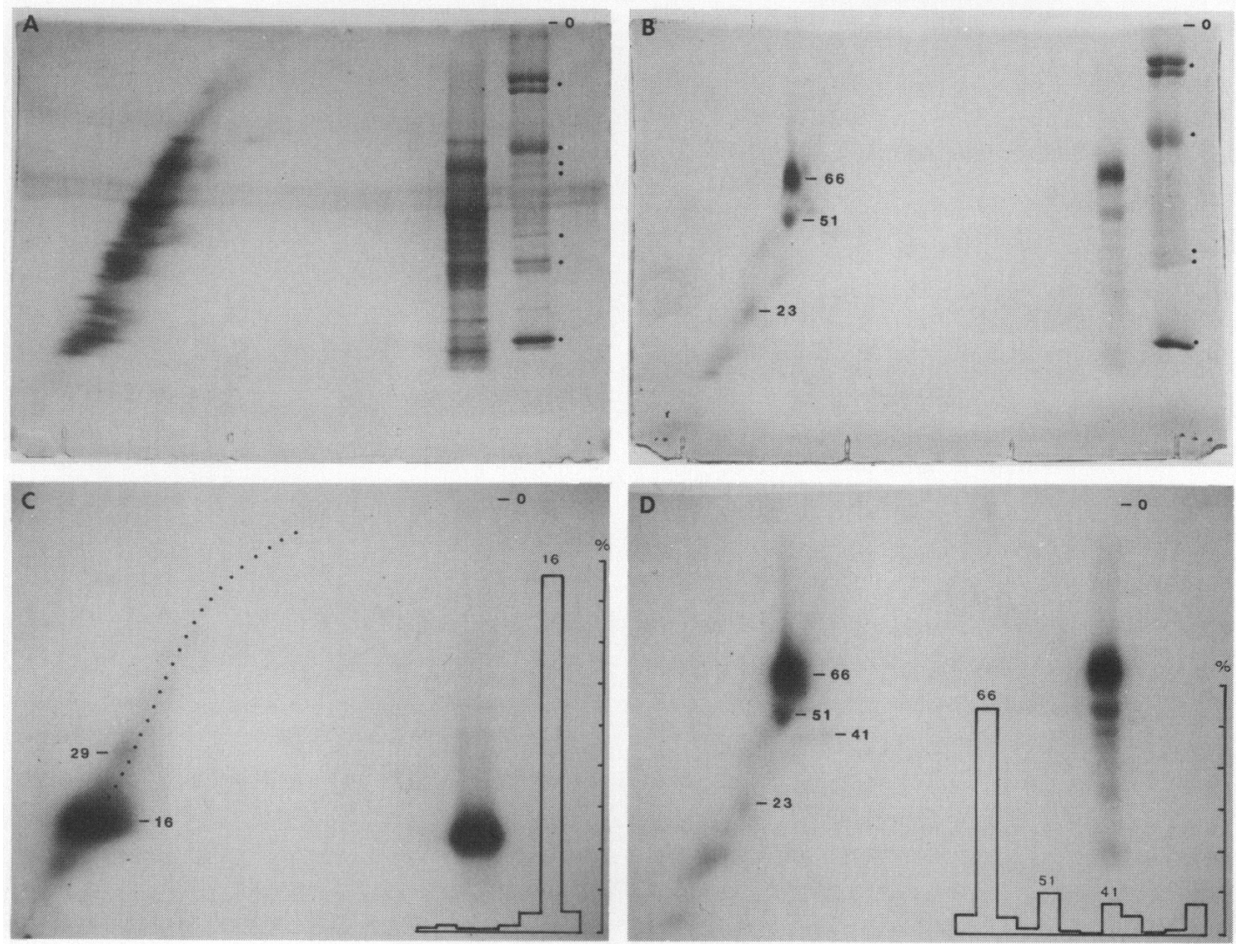

Fig. 4. Adsorption of fluid components $\left(\times 10^{-3}\right)$ by unlabelled cauda spermatozoa incubated in ${ }^{125}$ I-labelled uterine fluid for $1 \mathrm{~h}$ : (A, B) staining pattern of spermatozoa (A) and fluid (B), (C, D) corresponding autoradiographs and radioactivity distribution (inserts). Note selective enrichment of an $M_{\mathrm{r}} 16000$ fluid component on the sperm surface in (C).

6C. With the exception of the $M_{\mathrm{r}} 24000$ component which is actively adsorbed by 'capacitated' spermatozoa in cauda fluid, surface renovation of cauda spermatozoa after exposure to female genital tract fluids apparently did not involve polypeptides that were identical or similar to the species lost from the sperm surface in female reproductive tract secretions. Although numerous labelled proteins appeared on the surface of spermatozoa during incubation in radioiodinated cauda fluid after they had been exposed to uterine and oviduct fluids, certain fluid components that were 'minor' were preferentially incorporated into the plasma membrane (i.e. $M_{\mathrm{r}} 76000$ ).

\section{Motility}

Spermatozoa incubated in uterine fluid displayed an exceptionally high motility. All sperm samples incubated in this fluid for $1 \mathrm{~h}$ consistently received the highest motility score (5). In fact, the motility of such spermatozoa was of a magnitude that required a much higher $\boldsymbol{g}$ force than usual to separate spermatozoa from the fluid (see 'Materials and Methods'). Closer inspection revealed a directional head-to-head agglutination between 2-4 spermatozoa. The coordinated flagellation of such an array gave the spermatozoa a much higher velocity than would have been the case with single cells. After a further $3 \mathrm{~h}$ incubation in oviduct fluid, following exposure to uterine fluid, the spermatozoa had separated again and had resumed a motility pattern that was comparable to that of freshly collected cells. 

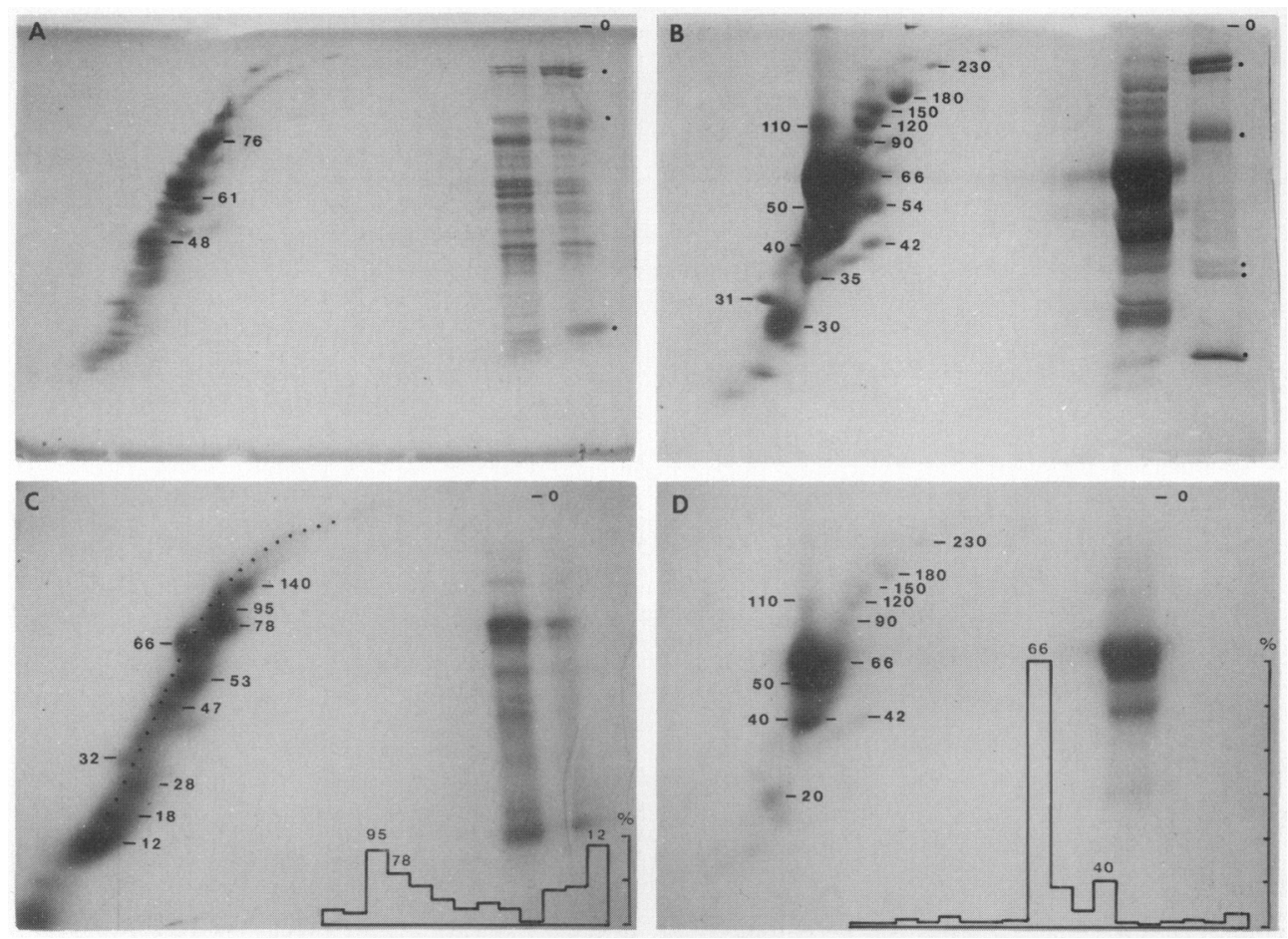

Fig. 5. Adsorption of exogenous fluid components $\left(\times 10^{-3}\right)$ by unlabelled cauda spermatozoa incubated in radioiodinated oviduct fluid for $3 \mathrm{~h}$ after exposure to unlabelled uterine fluid for $1 \mathrm{~h}$. Arrangements of panels as in Fig. 4.

\section{Discussion}

The observed changes in surface labelling patterns during incubation in female and male reproductive tract fluids in vitro demonstrate the feasibility of the present approach. The end point of capacitation is presumably reached when a significant proportion of spermatozoa undergo spontaneous acrosomal reaction on addition of $\mathrm{Ca}^{2+}$ (Yanagimachi, 1981). This has been verified in our laboratory using a triple stain technique (Talbot \& Chacon, 1981) on cauda epididymal spermatozoa after incubation in uterine or uterine and oviduct fluids diluted $(1: 1, \mathrm{v} / \mathrm{v})$ with calcium-free BWW medium or dialysed against calcium-free BWW medium; after $1-5 \mathrm{~h}$, the percentage of spermatozoa undergoing the acrosomal reaction on addition of $\mathrm{Ca}^{2+}(2.5 \mathrm{~mm})$ was about twice that of spermatozoa incubated in a synthetic BWW medium for the same period of time (22-24.3\% versus $12 \%$; A. Reyes, M. E. Chavarria \& J. K. Voglmayr, unpublished observations).

The average interval between peaks of fluid secretion agrees well with the length of the oestrous cycle reported for other breeds of sheep (Iritani, Gomes \& VanDemark, 1969; Sutton, Nancarrow, Wallace \& Rigby, 1984). This increase in the flow of fluid is presumably due to the influence of oestrogen which is known to increase capillary blood flow (Brown \& Mattner, 1977) and the secretory activity of the epithelium of the oviduct (Edwards, 1980). However, the maximal daily output of oviduct fluid $(7 \mathrm{ml})$ in Dorset ewes exceeded by several times the daily tubal secretion of entire and ovariectomized Merino ewes treated with oestradiol compounds (Restall, 1966b). In the present study no attempts have been made to compare early and mid-season cycles. Nevertheless, 

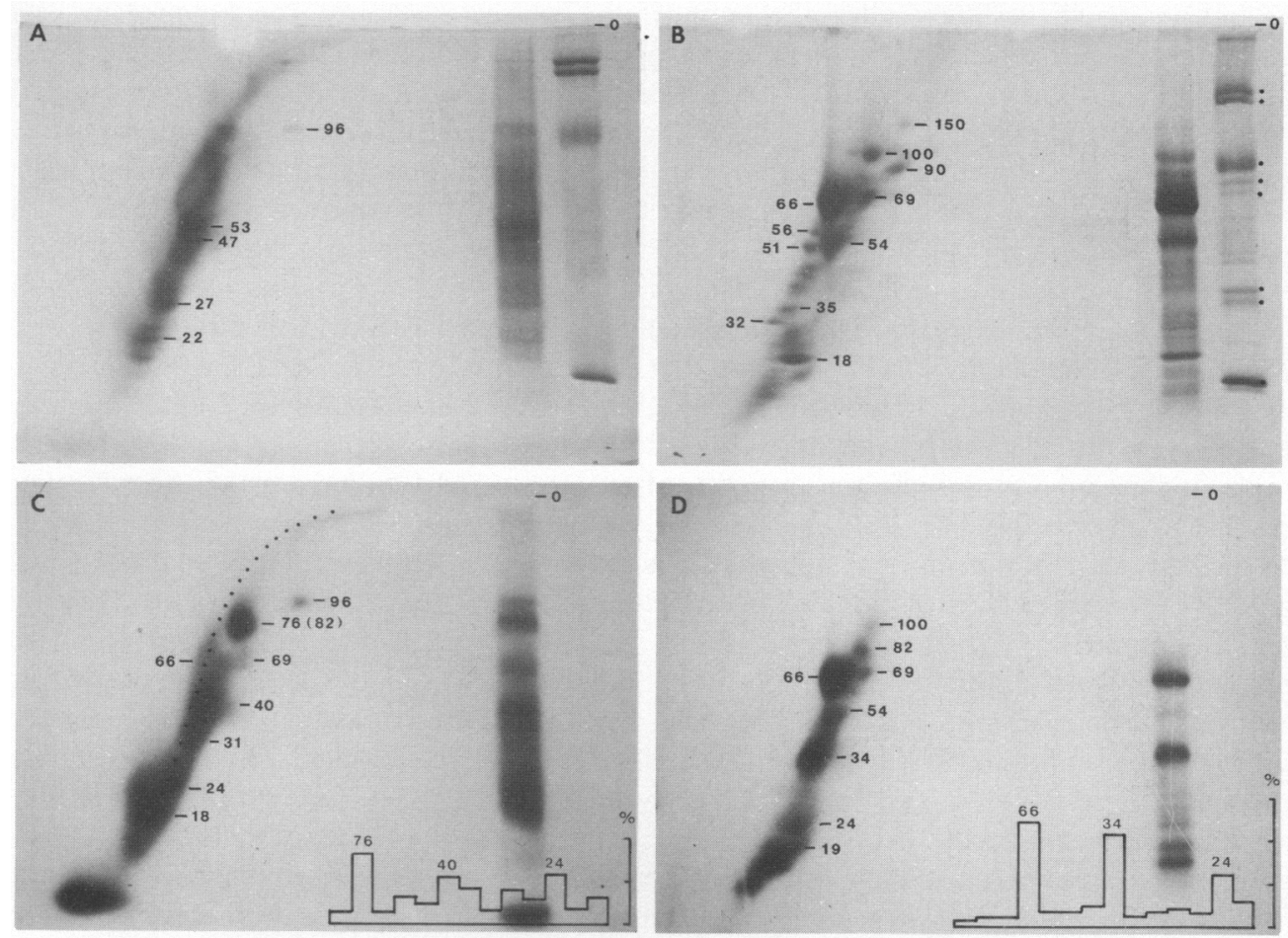

Fig. 6. Adsorption of exogenous fluid components $\left(\times 10^{-3}\right)$ by unlabelled cauda spermatozoa incubated in radioiodinated cauda epididymal fluid for $2 \mathrm{~h}$ after exposure to unlabelled uterine and oviduct fluids for $1 \mathrm{~h}$ and $3 \mathrm{~h}$, respectively. Arrangements of panels as in Fig. 4.

we found that the periovulatory increase in fluid secretion was greatest during the early breeding season (September-October; Murray, Goode \& Linnerud, 1969). Like Sutton et al. (1984) we consistently observed increased secretion of oviduct fluid 3-4 days after the major peak.

The electrophoretograms of uterine and oviduct fluid showed that the most prominent component appeared with a mobility similar to that of serum albumin $\left(M_{\mathrm{r}} 66000\right)$. This confirms the findings of Sutton et al. (1984) for oviduct fluid of Merino ewes, but we were unable to corroborate their observation of an $M_{r} 80000-90000$ glycoprotein which appeared in oviduct fluid at the time of ovulation. This discrepancy could be explained by differences in breed (Dorset versus Merino), hormone treatment (progesterone implants were used by the Australian workers) or animal preparation. In the present study the utero-tubal junctions were ligated and uterine and oviduct fluids were collected separately. As can be seen in Fig. 1, uterine fluid flowed only for a brief period (3-4 days) during each cycle. It might be expected, therefore, that in the non-ligated preparation fluid would pass from the uterus into the oviducts, thereby contributing for $3-4$ days to the protein composition of oviduct fluid. This may explain the changes in the macromolecular composition of oviduct fluid during the oestrous cycle of the ewe (Sutton et al., 1984).

Our results showed that specific losses of surface components may cause a shift in the surface protein pattern. At the same time exogenous fluid components were selectively enriched on the sperm cell surface. The regionalization of the ram sperm membrane (Wolf \& Voglmayr, 1984) and the 'patchwork quilt-like' topography of protein-poor, high fluidity and protein-rich, low fluidity areas (Friend, Orci, Perrelet \& Yanagimachi, 1977) would make it possible that loss and adsorption of proteins are taking place at the same time. Specific losses of surface components during sperm 
capacitation would certainly alter the permeability characteristics of the lipoprotein plasma membrane and increase $\mathrm{Ca}^{2+}$ flux which then triggers the acrosomal reaction (Yanagimachi, 1981).

Equally if not more important for functional changes of spermatozoa may be adsorbed exogenous fluid components. For example, the selectivity by which certain fluid components were enriched on the sperm surface, especially from uterine fluid and their intimate association with the plasma membrane as evidenced by the fact that they could not be removed by repeated washing, would make them likely candidates for a functional role in promoting sperm capacitation. The enrichment of such a component on the cell surface may be by itself a factor in sperm capacitation, or it may prepare the spermatozoon for subsequent interaction with oviduct fluid components as part of a mechanism underlying a synergistic effect of sequential exposure to different fluid environments along the female tract (Bedford, 1969). Our observation that dialysis against a synthetic medium did not lower the potency of uterine fluid to capacitate spermatozoa points to a polypeptide in this fluid as the effective constituent (A. Reyes, M.E. Chavarria \& J.K. Voglmayr, unpublished observations).

The adsorption pattern of spermatozoa in cauda epididymal fluid, after incubation in female genital tract secretions (Fig. 6) showed that surface renovation of capacitated spermatozoa involves several components. It is difficult, therefore, to judge on the basis of selective adsorption which components of cauda fluid are important for surface renovation or to speculate on the nature of the decapacitation factor(s) and its distribution over the sperm surface. Nor is it possible at this stage to compare proteins adsorbed by ram spermatozoa from cauda fluid with similar functional components identified in other species, especially since the factor itself may be small and may be attached to a large molecule (Williams, Abney, Chernoff, Dukelow \& Pinsker, 1967). Attempts to characterize components lost or adsorbed by spermatozoa by applying labelling procedures specific for carbohydrate residues (i.e. galactosyl, galactosaminyl, sialyl termini) were inconclusive (not shown). These probes were detrimental to spermatozoa and could be used only after the cells had been incubated in the fluids.

The increased motility of ram spermatozoa incubated in uterine fluid was not unexpected in the light of previous reports on the hyperactivation of capacitated spermatozoa from other species (Yanagimachi, 1981) and it supports our claim that the active component resides in this fluid. Further studies to purify and characterize such polypeptides should be pursued with high priority, especially as they may shorten the time required to capacitate spermatozoa. Since spermatozoa from one species can be capacitated in the female tract of another species (see Chang \& Hunter, 1975), these fluid components may be successfully used in Al programmes for domestic animals or they may be applied to human semen for in-vitro fertilization.

We thank Dr Alejandro Reyes for assistance and suggestions in surgery during the initial phase of this project; Miss Margaret-Ellen Allshouse for technical assistance; and Miss Michelle Pujol for typing the manuscript. This work was supported by USPHS grant HD-18874 and in part by a private grant from the Mellon Foundation.

\section{References}

Austin, C.R. (1951) Observations on the penetration of the sperm into the mammalian egg. Aust. J. Sci. Ser. B4, 581-596.

Bedford, J.M. (1969) Limitations of the uterus in the development of the fertilizing ability (capacitation) of spermatozoa. J. Reprod. Fert., Suppl. 8, 19-26.

Bretscher, M.S. (1971) Major human erythrocyte glycoprotein spans the cell membrane. Nature, Lond. 231, 229-232.
Brown, B.W. \& Mattner, P.E. (1977) Capillary blood flow in the genital tracts of conscious ewes: cyclic changes and the effect of ovarian hormones. $J$. Endocr. 74, 185-191.

Chang, M.C. (1951) The fertilizing capacity of spermatozoa deposited into the Fallopian tubes. Nature, Lond. 168, 697-698.

Chang, M.C. \& Hunter, R.H.F. (1975) Capacitation of mammalian sperm: biological and experimental 
aspects. In Handbook of Physiology, vol. 5, pp. 339-351. Eds D. W. Hamilton \& R. O. Greep American Physiological Society, Washington, D.C.

Cornett, L.E. \& Meizel, S. (1978) Stimulation of in vitro activation and the acrosome reaction of hamster spermatozoa by catecholamines. Proc. natn. Acad. Sci. U.S.A. 75, 49544958

Davis, B.K., Byrne, R. \& Bedigia, K. (1980) Studies on the mechanism of capacitation: albumin-mediated changes in plasma membrane lipids during in vitro incubation of rat sperm cells. Proc. natn. Acad. Sci. U.S.A. 77, 1546-1550.

Edwards, R.G. (1980) The female reproductive tract. In Conception in the Human Female, pp. 416-524. Academic Press, London.

Fairbanks, G., Steck, T.L. \& Wallach, D.F.H. (1971) Electrophoretic analysis of the major polypeptides of the human erythrocyte membrane. Biochemistry, N.Y. 10, 2606-2617.

Farooqui, A.A. (1983) Biochemistry of sperm capacitation. Int. J. Biochem. 15, 463-468.

Fraser, L.R. (1984) Mouse sperm capacitation in vitro involves loss of a surface-associated inhibitory component. J. Reprod. Fert. 72, 373-384.

Friend, D.S. (1980) Freeze-fracture alterations in guinea pig sperm membranes preceding gamete fusion. In Membrane-Membrane Interactions, pp. 153-165. Ed. N.B. Gilula. Raven Press, New York.

Friend, D.S., Orci, L., Perrelet, A. \& Yanagimachi, R. (1977) Membrane particle changes attending the acrosome reaction in guinea pig spermatozoa. $J$. Cell Biol. 74, 561-577.

Iritani, A., Gomes, W.R. \& VanDemark, N.L. (1969) Secretion rates and chemical composition of oviduct and uterine fluids in ewes. Biol. Reprodk 1, 72-76.

Liu, C.-C., Fairbanks, G. \& Palek, J. (1977) Spontaneous, reversible protein cross-linking in the human erythrocyte membrane. Temperature and $\mathrm{pH}$ dependence. Biochemistry, N.Y. 16, 4066-4074.

Markwell, M.A.K. \& Fox, C.R. (1978) Surface-specific iodination of membrane proteins of viruses and eucaryotic cells using 1,3,4,6-tetrachloro-3 $\alpha, 6 \alpha$-diphenylglycoluril. Biochemistry, N.Y. 17, 4807-4818.

Mattner, P.E. (1963) Capacitation of ram spermatozoa and penetration of the ovine egg. Nature, Lond. 199, $772-773$.

Mattner, P.E. \& Voglmayr, J.K. (1962) A comparison of ram semen collected by the artificial vagina and by electro-ejaculation. Aust. J. exp. Agric. Anim. Husb. 2, $78-81$.

Meizel, S. (1984) The importance of hydrolytic enzymes to an exocytotic event, the mammalian sperm acrosome reaction. Biol. Rev. 59, 125-157.

Meizel, S. (1985) Molecules that initiate or help stimulate the acrosome reaction by their interaction with the mammalian sperm surface. Am. J. Anat. 174, 285-302.

Murray, F.A., Goode, L. \& Linnerud, A.C. (1969) Effects of season, mating and pregnancy on the volume and protein content of ewe oviduct fluid. J. Anim. Sci. 29 , $727-733$.
O'Rand, M.G. (1982) Modification of the sperm membrane during capacitation. Ann. N.Y. Acad. Sci. 383, 392-404.

Restall, B.J. (1966a) The Fallopian tube of the sheep. I. Cannulation of the Fallopian tube. Aust. J. biol. Sci. 19, 181-186.

Restall, B.J. (1966b) The Fallopian tube of the sheep. II. The influence of progesterone and oestrogen on the secretory activity of the Fallopian tube. Aust. J. biol. Sci. 19, 187-197.

Singh, J.P., Babcock, D.F. \& Lardy, H.A. (1978) Increased calcium-ion influx is a component of capacitation of spermatozoa. Biochem. J. 172, 549-556.

Sutton, R., Nancarrow, C.D., Wallace, A.L.C. \& Rigby, N.W. (1984) Identification of an oestrus-associated glycoprotein in oviducal fluid of the sheep. $J$. Reprod. Fert. 73, 415-422.

Talbot, P. \& Chacon, R.S. (1981) A triple-stain technique for evaluating normal acrosome reaction of human sperm. J. exp. Zool. 215, 201-208.

Talbot, P. \& Franklin, L.E. (1978) Surface modification of guinea pig sperm during in vitro capacitation: an assessment using lectin-induced agglutination of living sperm. J. exp. Zool. 203, 1-14.

Umbreit, W.W., Burris, R.H. \& Stauffer, J.F. (1959) Manometric Techniques in Tissue Metabolism. Burgess Publishing Co., Minneapolis.

Voglmayr, J.K., Scott, T.W., Setchell, B.P. \& Waites, G.M.H. (1967) Metabolism of testicular spermatozoa and characteristics of testicular fluid collected from conscious rams. J. Reprod. Fert. 19, 87-99.

Voglmayr, J.K., Musto, N.A., Saksena, S.K., Brown-Woodman, P.D.C., Marley, P.B. \& White, I.G. (1977) Characteristics of semen collected from the cauda epididymidis of conscious rams. J. Reprod. Fert. 49, 245-251.

Voglmayr, J.K., Fairbanks, G., Jackowitz, M.A. \& Colella, J.R. (1980) Post-testicular developmental changes in the ram sperm cell surface and their relationship to luminal proteins of the reproductive tract. Biol. Reprod. 22, 655-667.

Voglmayr, J.K., Fairbanks, G., Vespa, D.B. \& Colella, J.R. (1982) Studies on mechanisms of surface modifications in ram spermatozoa during the final stages of differentiation. Biol. Reprod. 26, 483-500.

Williams, W.C., Abney, T.O., Chernoff, H.N., Dukelow, W.R. \& Pinsker, M.C. (1967) Biochemistry and physiology of decapacitation factor. J: Reprod. Fert., Suppl. 2, 11-23.

Wolf, D.E. \& Voglmayr, J.K. (1984) Diffusion and regionalization in membranes of maturing ram sperm. J. Cell Biol. 98, 1678-1684.

Wright, R.W., Jr \& Bondioli, K.R. (1981) Aspects of in vitro fertilization and embryo culture in domestic animals. J. Anim. Sci. 53, 702-729.

Yanagimachi, R. (1981) Mechanisms of fertilization in mammals. In Fertilization and Embryonic Development in Vitro, pp. 81-182. Eds L. Mastroianni, Jr \& J. D. Biggers. Plenum Press, New York.

Received 7 November 1985 